\title{
The Research of Using Animation Design to Promote the Tourism Economy Under the Guilin Folk Cultural Characteristics
}

\author{
ZHANG Yu-ting \\ Guilin University of Aerospace Technology, \\ Guilin, Guangxi, China \\ 920070961@qq.com
}

\author{
Liu Zhi-hong \\ Guangxi Normal University, \\ Guilin, Guangxi, China \\ 261607194@qq.com
}

\begin{abstract}
Guilin is not only a minority living area that full of profound folk cultural but also a world famous tourism city. Research and analysis of the Guilin folk culture, give full play to its inheritance and creativity and display in the form of animation, it is a meaningful exploration and research for the transmission of culture, tourism development, the promotion of local economy. From the renewal of the concept to the adjustment of mode, to penetrate the local folk culture animated design, can promote the development of local animation design, this also allows the local tourism more competitive advantages and characteristics.
\end{abstract}

Keywords- folk culture; animation design; digital technology; tourism economy

\section{INTRODUCTION}

Foreign scholars began to study art and tourism from nineteen nineties. Urry ( 1990) in his " The Joy of Travel " pointed out: " the tourism destination that the tourists selected is based on the entertainment, realizing dream, the desire for participation and the desire is made of some factors that are not tourism elements, such as film, television, literature and magazines and so on".Visible, targeted marketing of commercial animation can attract people by the unique effects to the propaganda animation to travel. Currently, in Europe ,the United States, Japan and South Korea. profit value and comprehensive benefits that created by the emerging animation tourism and cultural creative industries are larger than that created by the traditional automobile manufacturing, oil and energy industries and other entities of economy, and it has been another world big

new knowledge economy. For example, Disney animation culture industry, through the development of the theme park, extends to the global tourism industry and creates a huge economic value. Japanese and Korean animation "Ultraman", "Crayon" cultural and creative products quickly spread throughout the world and attract a large number of overseas tourists to visit tourist cultural animation base.

In recent years, China's rapid development of animation industry shows a vigorous development of the state of affairs. In particular, the application of network technology, such as online advertising, MMS, mobile media, provides more ways

Project Source:

1.2011 Guangxi the new century education reform project: The higher vocational animation professionals combine culture with the folk culture of Guilin practical teaching and research (2011JGA162), Project Moderator: Zhang Yu-ting;

2.Department of Guangxi Philosophy and Social Sciences "12th Five-Year Plan 2011 Youth Foundation of Guilin local folk culture of animation designed to promote research on the development of tourism economy" One of the outcomes (item number: 11FJY036), Project Moderator: Zhang 520 Yu-ting; and broader platform for the dissemination of commercial animation. Fairy color Ocean Park in Hong Kong is the only one to enter the Forbes top ten theme parks around the world ranked seventh. Shenzhen Window of the World and China Folk Customs Park created by OCT Group draw on Western fairy tale theme park mode, by folk cultural propaganda, they access to the economic and cultural effects of attention, and promote the development of tourism The rapid development of the Anime tourism and creative industries in the Yangtze River Delta region, where established a Water Margin City, Three City and so on, has been the success stories of native culture used in the animation industry and tourism phase conjugate. 2010 China. Shanghai World Expo China Pavilion, " Qingming Riverside " made into a large ink animation projection to show the visitors vividly the living conditions of the Song Dynasty, it is another precedent animation successfully applied in the tourism industry. The second session of "China. Guilin innovative creative cultural festival cum Guilin International Cartoon and Animation Festival "held in Guilin, in October 2010, this fully reflects that Guilin municipal government attaches great importance to the development of cultural and creative industries. It is of an important practical significance that Making full use of this platform and the animation industry to promote the study of Guilin tourism .

\section{GUILIN IS NOT ONLY A TOURIST CITY BUT ALSO A CIVILIZED ANCIENT CITY WITH DEEP FOLK CULTURE}

Guilin is a famous tourist city in the world. It is also one of the first 24 historical and cultural cities. Geographically, as a transportation hub Zhongyuan and Lingnan, Guilin absorbed Wuyue Culture, Central Plains Culture and Jingchu Culture, it formed its own unique cultural characteristics. From Zhen $\mathrm{Pi}$ culture to resistance culture, the artistic value of its heritage can be comparable with the artistic value of $\mathrm{Wu}$ and Yue. Cliff, Guihai Forest of Stone Tablets, Ruin of the monument, blue and white plum bottles in Guilin documented a lofty historical and artistic value of the economy, culture, architecture, painting, folk, ethnic relations in the 1,700 years [1] Guilin Features unique cultural customs of the ethnic minorities, such as Zhuang, Dong, etc, is also the artistic treasures of high research value. From the dealer the construction of the lever bar to Liu San Jie's Song Festival, the Huaqun blouse of the young people, ceremonial musical instruments, and all of these imply a rich local culture [2] 
Guilin Nuo culture is a bright pearl in the local folk cultures. Song Dynasty, Guilin was Nuo art center. In 2006, the Nuo opera was selected for the first batch of national intangible cultural heritage directory. Today, Guilin Yao Nuo mask production process level is among the nation's top spear, the Fuli town in Yangshuo county, Pingle County, Longsheng County and so on have a heritage of Nuo culture. Guilin Nuo culture is an important part of traditional Chinese culture, and vigorously carries forward to it and creates economic value for the local, inheritance and protection of intangible cultural heritage in China is of great significance.

\section{COMBINATION OF TRADITIONAL AND MODERN, USING THE FOLK CULTURE ANIMATION DESIGN TO PROMOTE THE DEVELOPMENT OF GUILIN LOCAL TOURISM}

The design and creation of the animation is inseparable from cultural support. We can not just unconventional, or drift, we should be down to earth from the study of the local culture, explore new ideas and create animation design with a rich Guilin culture and Guilin Features.

The performances with animation form of the spiritual and cultural essence of Guilin Nuo masks art, Nuo song, Exorcise, Nuo opera and so on can Facilitate the latter part of tourism promotion and construct tourism promotion of the Guilin Tourism shaping and the cultural connotation image, and drive the promotion of other attractions. Among the Guilin Gongcheng Yao God Nuo array, Lingui Nuo opera, Longsheng Furong Village Nuo opera,Yangshuo maoshan Nuo masks, Mazu Festival Exorcise etc, we select typical representative of the specific case, study and analysis the market, tap the local traditional cultural elements and create commercial animation clips design, by this way, we can carry forward the local culture and attract tourists. for example, Guangxi Guilin Shigong play belongs to amuse and entertain Nuo activities, it is a form of expression of the local Nuo. It's position in the theatrical community as much as the wedge, Pihuang, lantern system opera. Art aesthetic, its early manifestations of the Shigong misfortunes in praying for the people, exorcism and illness, bring the mask of God, the pretexting God fell, side song while dancing. Hard creation of folk artists created the world rare Nuo art three- layer-mask ------ The Lee King with original red face, white face of the charity and golden fierce physiognomy [3] multi-faceted of God in Nuo masks wrote a glorious page in the folk culture history of the human. With the expansion and development of the repertoire, the Shigong play, generally with no mask, minority song and dance with the woodcut masks or paper masks, and most use make-up method of shaping the character. [4] Its song and dance performances, absorbed Guilin folk music and customs of the local dance, masks, makeup, clothing, the track, screenplay, singing and so on, are all local Zhuang folk profound reflection and reflect the deep cultural, artistic and mysterious. The Shigong opera were all created by farmers and few scholars participated, these operas have the unique beauty of simplicity and beauty. Another example, annual Lunar May eighth day is a duration of local tradition at Fuli town Yangshuo county in Guilin, The local held worship Mazu and amusement God folk cultural activities. Villagers headband Nuo face, singing, lion dance, playing card lights, on stilts, the Eight Immortals Zhizha, gongs canopy, story station, Hanchuan ......, the scene is very spectacular. These reflect the local characteristics of the folk style and the national spirit, and these activities have a wealth of tourist viewing content, profound cultural connotations, Diversification of the combination of entertainment and learning has become one of the highlights to attract tourists, has become a bright spot to attract tourists. However, this custom activities, drama performances, are all with the unique nature of the intangible cultural heritage, heritage, nationality and other characteristics, as well as regional, real-time and variability characteristics inevitably, So Looking for a suitable form of heritage, promote and disseminate them is of an important significance.

Guilin local has a rich cultural atmosphere, a wealth of national characteristics and culture, a large number of folk artists. Splash-ink landscape painting, freehand with Chinese traditional characteristics of Chinese painting is the main representative of the Guilin characteristic forms of artistic expression. They use local resources and art forms and turn unique folk culture of Guilin folk into Animation art. for example, sort out, heritage the folk culture such as Nuo opera, Exorcise, Nuo masks, and make them into a cartoon short form, Make Guilin attractions and beautiful scenery, local specialties, folk customs design into animation in the form of the picturesque Ink animation, humor, video clips, they are not only convenient to non-material cultural heritage protection but also ease of folk culture tourism promotion. By means of animation design in the form of the local culture to promote Guilin local tourism business promotion, to carry forward the heritage of the indigenous folk culture of Guilin, to shape the image of civilized cities in Guilin, to highlight Guilin cultural and spiritual connotation, and it is in line with the home and abroad trend that vigorously promote the development of animation industry and the local modern tourism advertising.

\section{TO DEVELOP THE TOURISM ECONOMY WITH TOURISM PROMOTION IN THE DIGITAL TECHNOLOGY}

With the continuous development of computer digital technology, Animation software changes with each passing day, Currently on the market there are many 2D animation software ,such as ANIMO, USANIMATION, TOONZ, RETAS PRO, Harmony, Toon Boom Studio and FLASH, the cartoon, such as " Naruto ", " death ", " one piece ", " Princess ", produced in these 2D software reflected exquisite hand-painted skills of animators. 3D software is 3D MAX, MAYA, LIGHTWAVE, SOFTIMAG, etc. and " ice age ", " cars ", " Monsters Inc ", " tumblebugs ", " Madagascar ", " magic "and so on are all designed by 3D animation. The development of computer software technology rapidly promotes the animation design reach a new level. [5]

China Ink animation is a product of the combination of the traditional Chinese painting with Chinese national characteristics and animation, it uses the computer technology to simulate Chinese painting, pen and ink effect, and emphasizes the painting and the mood. For example, the design style of the famous painter Qi Baishi's "Little Tadpole Looking for Mom", with the style of the famous painter $\mathrm{Li}$ Keran "reed pipe" design, all these reflect a strong wind. So we can use traditional classical techniques to design draw a Guilin local folk legends, festivals, local opera, such as Caidiao , Gui opera, the Shigong drama, etc., and then combine with the television, Internet, mobile media, outdoor 
media, DM ad and other means of communication to most vividly demonstrate these in front of the tourists and allow tourists refreshing. Tranforming the traditional static forms of tourism promotion into animation form of dynamic publicity has become a new trend of the development of a modern tourism advertising, it has a wide range of publicity, high speed, high efficiency advantage of the characteristics. Such publicity is more popular than the publicity of the various tourist company printed flat better guide consumption.

The development of tourism economy needs to stimulate tourism consumption, the tourists consumer psychology internal factors are perception ,need, motivation, personality, attitude, learning. Travel motivations of historical motivation has four factors: Traveling for health, for education, for seek spiritual values, for self relax .[6]With natural scenery and cultural landscape in Guilin tourism factors, vivid animation design promotions enhance the attractiveness of scenic spots in Guilin, can better mobilize tourists perception, stimulate the tourism needs of inspired travel motivation. When the tourists have the motivation, with the internal driving force, the tourists will be positive for the realization of the goal and action. [7] Make full use of local culture commercial animation to promote culture connotation of Guilin tourism, and take the following the route of transmission: release the commercial animation design film with local characteristics in the network, on removable media in city buses, train station, bus station exit, center square and other large electronic screen. We can also be associated with China Mobile, China Unicom cooperation, using MMS ways to do publicity on the mobile phone that roam to Guilin for attract tourism consumers. This user-friendly mode of transmission allows tourists willing to accept psychologically. [8] They are also more particularly to attract tourist groups with photography, animation painting, and other preferences as well as family tourists with children. This tourism promotion way avoid the psychological offensive that tough boring tamponade tourism advertising bought to the visitors, and achieve the purpose to promote Guilin economy.

\section{CONCLUSIONS}

Digging out Featuring Nuo culture from many folk culture, combining of art and culture, combining of art and business, combining of traditional folk culture and modern digital means , all of these have important practical significance and research value to promote Guilin tourism and local economic development and to make contribution to Guangxi region economy, in the new digital era, it is also a new trend in tourism promotion.

\section{REFERENCES}

[1] Peng Huizhi.National folk aesthetics[M].Guilin: Guangxi Normal University Press,2000.

[2] ZHANG Yu-ting,YE Gui-chen.The Application Research of Animation Design Education Reform Based on the Folk Culture[J]. Guangxi Education, 2012(7): :28-29.

[3] Cheng Yue-hong, Xu Xing-jian,Qian ying-yu. Chinese Nuo Culture[M].Beijing: Central Compilation and Translation Press.2008.

[4] Guo Xiuzhi. Guangxi Institute of Certified Public play cross-talk [J]. Guangxi Nuo Art Proceedings, 1990 (17):102-104.

[5] Zhao Yun-lai. as art technology [J]. Television subtitles. Effects Animation,2004(7):56-57.

[6] Gan Chao-you. Tourist psychology [M]. Tianjin: Nankai Press, 2000.

[7] Du Wei, tourism and consumer behavior [M]. Tianjin: Nankai Press, 2009.

[8] Ma Yong, Li Yu-xi, Li Juan-wen. Tourism Planning and Development [M]. Beijing: Science Press,2004. 